\title{
Crimean Congo Haemorrhagic Fever: An Emerging Tick-borne Metazoonosis
}

\author{
S. H. Sindhi ${ }^{1 *}$, K. R. Bhedi ${ }^{1}$, J. B. Kathiriya ${ }^{1}$ and S. N. Ghodasara ${ }^{2}$ \\ ${ }^{1}$ Department of Veterinary Public Health and Epidemiology, \\ ${ }^{2}$ Department of Veterinary Microbiology, College of Veterinary Science and Animal \\ Husbandry, Junagadh Agricultural University, Junagadh, Gujarat, India \\ *Corresponding author
}

\section{A B S T R A C T}

\section{Keywords}

CCHF, Tick borne zoonoses, Meta zoonoses and Hemorrhagic fever

Article Info

Accepted:

18 May 2020

Available Online:

10 June 2020
Crimean-Congo Hemorrhagic Fever (CCHF) is an emerging tick-born zoonotic disease in India which is caused by Nairovirus of Bunyaviridae family. CCHF is reported from about 30 countries of the world. An outbreak of $\mathrm{CCHF}$ has been reported in Gujarat which killed four people including two physicians, one nurse and a rural housewife. Tick bite, contact with infected material and nosocomial routes are the main routes of infection. This disease is not much important in animals as animals are asymptomatic but domestic livestock play a vital role in the transmission of disease to humans. So the persons associated with animals like veterinarians, farmers and slaughter house workers are also at the high risk of getting the infection. The disease has a great public health importance.

\section{Introduction}

Infectious diseases are the leading contributors of mortality and morbidity in humans and animals across the globe. Many emerging diseases, even epidemics are a direct consequence of zoonosis. Some infectious diseases like viral hemorrhagic fevers (VHFs) are a matter of great concern due to their zoonotic nature and associated fatality. VHFs are now becoming a severe threat to animals and humans. Crimean-
Congo hemorrhagic fever (CCHF) is one of the most widely distributed viral hemorrhagic fevers among these (Mardani and Jahromi, 2007). It is an emerging zoonotic disease which has drawn attention of international community.

Although, it is new to India, outbreaks have been recorded from various countries in Africa, Asia, South-East Europe, and Middle East (Ergonul, 2006). CCHF is a tick born viral zoonotic disease caused by virus of 
genus Nairovirus of Bunyaviridae family. The disease is distributed globally which can be correlated by the global distribution of the tick vector (Hyalomma tick) which is responsible for viral transmission. The disease has been recognized by different names as Asian Ebola, Hungribta (blood taking), Khunymuny (nose bleeding) or Karakhalak (Black Death) in the different parts of world (Whitehouse, 2004).In the last 2 years, in India, $\mathrm{CCHF}$ is emerging as an important zoonotic disease and a potential threat for the persons associated with animals as farmers, animal handlers and veterinarians due to its potential transmission from animal to human. However, human-to-human transmission also reported in some cases in various countries (Ergonul, 2006).

\section{History}

CCHF was first described in the Crimea, Russia in 1944 by soviet scientists during an outbreak which involved 200 cases of CCHF in soviet military personnel. They called it Crimean hemorrhagic fever (CHF). Later in 1956 it was found that the causative agent was identical to a virus isolated from a patient in Congo and the name CCHF was adopted after that (Casals, 1969).

\section{Epidemiology and geographical distribution}

CCHFV has a most extensive geographic distribution among all tick viruses and it is widespread in Eurasia and Africa (Maltezou and Papa, 2011).The geographic distribution pattern of disease coincides with the distribution of Hyalomma tick vector. The virus is reported from about 30 countries which include Africa (Uganda, Sudan, Democratic Republic of Congo, Nigeria, Mauritania, Senegal and South Africa etc), Southeast Europe (Kosovo, Russia, Bulgaria, Greece and Turkey etc.), Middle East (Iraq,
Iran, Saudi Arabia and Oman) and Asia (Kazakhstan, Tajikistan, Uzbekistan, Pakistan, China and India) (Zavitsanou et al., 2009). In Africa, due to limited sanitary facilities, virus surveillance is difficult. In the last decade lesser than 100 cases were reported in Africa and most of the cases occurred in South Africa. In 2003, outbreak occurred in Mauritania and in 2008, a nosocomial outbreak was reported in Sudan. In Europe, Bulgaria is the only country where $\mathrm{CCHF}$ is endemic but outbreaks have been recorded with increased number of cases in other countries like Kosovo, Turkey, Albania, Ukraine and South-west of the Russian Federation. Between 1997 and 2009, a total of $159 \mathrm{CCHF}$ cases were identified in Bulgaria. In Turkey also, an increased number of CCHFcases were reported between year 2002 and 2009(Ozdarendeli, et al., 2010). CCHF is also widespread in Asia and middle-east (Ergonul, 2006). Recently in September of 2010, an outbreak wasreported in Pakistan's Khyber Pakhtunkhwa province.In Pakistan high incidence is common between March and May, and again between August and October, showing biannual surge(Sheikh, et $a l ., 2005)$. So, India is always at potential risk of acquiringCCHFV from its neighbors. Climatic change is always a contributing factor for the occurrence of disease that affects the reproduction of tick population resulting in increased incidence of tick born infections (Estrada-Pena, 2001).

\section{Gujarat}

The first documented outbreak of CCHF in India was reported from Ahmedabad, Gujarat province of western India in December 2010. Four human deaths occurred among which the first victim a 32-year old housewife of Korat village in Sanand died on January $3^{\text {rd }}, 2011$ (Mourya, et al., 2012). The 35-year-old doctor treating her died on $13^{\text {th }}$ January, 2011 and an accompanying nurse died on $18^{\text {th }}$ 
January, 2011(Patel, et al., 2011). The National Institute of Virology (NIV), Pune confirmed the positive testing of CCHFV, identified for the first time in India. A 25year-old doctor working as a medical intern became the next victim of $\mathrm{CCHF}$ virus and died on 31st January. He was the second doctor and fourth victim overall to die of deadly disease in Ahmedabad. All deaths have occurred in less than a month (Khan, et al., 2011). The death pattern shows that all the persons died of $\mathrm{CCHF}$ were living in close association of livestock or were the doctors treating the infected cases.

\section{Transmission from tick or animal-to- human}

Animalsdo not show clinical signs but may act as a source of infection for humans. The virus is transmitted from animals to humans either by direct contact with blood or tissue of infected animal. The tick biting or crushing of tick on skin or mucous membrane may be potential routes for transmission of CCHFV from tick to human (Ergonul, 2013).

\section{Human-to-human transmission}

Human- to human transmission occurs by direct contact of virus contaminated blood or tissues from infected patient. This may occur primarily in hospital setting causing nosocomial infection. Aerosol or airborne infection is also reported in Russia. There may be horizontal transmission from a mother to her child which indicates the need of preventive measures for in-house outbreaks of CCHF (Masayuki, et al., 2004).

\section{Causative agent}

CCHFV is a member of Nairovirus genus of the Bunyaviridae family. It is enveloped spherical virus approximately $100 \mathrm{~nm}$ in diameter (Whitehouse, 2004).
The lipid envelope is host derived, 5-7 $\mathrm{nm}$ thick, through which glycoprotein spikes, 8$10 \mathrm{~nm}$ in length protrude out. The genome, around $19.2 \mathrm{~kb}$, consists of three segments of negative sense single stranded RNA segments designated as Large (L), Medium (M) and Small (S) and encode for viral polymerase (L),Glycoprotein precursor (GPC) and Nucleocapsid (N)respectively (Yadav, et al., 2013).

\section{Phylogenetic diversity in cchfv}

Previous studies based on serological testing suggested very few significant differences among CCHFV strains (Casals, 1969). However, studies based on nucleic acid sequencing analysis revealed extensive global genetic diversity. The phylogenetic study of various $\mathrm{CCHFV} S, \mathrm{M}$ and $\mathrm{L}$ segment sequences available revealed the formation of distinct groups. The virus isolates circulating in our neighboring country Pakistan is having considerable variation in $\mathrm{S}$ segment sequence from the Indian isolates. The Indian isolates were found as a South-Asia 2/M2 far-east virus combination and it may be an intragenotypic reassortant (Yadav, et al., 2013).

\section{Reservoir and vector}

Like other tick born zoonotic agents, CCHFV follows an enzootic tick-vertebrate-tick cycle. There is no evidence of clinical disease in animals but a wide range of domestic and wild animals act as reservoir for $\mathrm{CCHFV}$ (Ergonul, 2013).The CCHFV has been isolated from various domestic and wild animals including cattle, sheep, goats, hares, hedgehogs, mice (Mastomys spp.) and domestic dogs. On serological testing the antibodies against CCHFV has been found in various wild and domestic animals even in a Tortoise in Tajikistan. Most of the birds are thought to be resistant to CCHF infection; however, some reports are available in 
ostriches where experimentally infection was produced. In South Africa, cases have been reported where the persons working in commercial ostrich slaughter house suffered from disease. Birds may transfer the virus infected ticks even though they themselves remain non-viremic.In a study recently $\mathrm{CCHF}$ was detected in the ticks from migratory birds in Morocco (Palomar, et al., 2013). So the migratory birds may be a reason of transport of virus from one place to other distinct places. Apart from migratory birds, international trade and transport of livestock carrying ticks may transport virus from one country to other (Palomar, et al., 2013).

Tick act as both reservoir as well as vector for CCHFV. CCHFV can infect a number of ticks of Ixodidae family but particularly ticks of genus Hyalomma are the most common and efficient vectors of CCHFV (WHO, 2013) Transovarial, transtadial and venereal mode of transmission of virus is found in vector. So the tick remains infected throughout its life and transfer virus from one generation to next generation. Immature ticks feed on the blood of small animals while the mature tick transfer infection to large animals including domestic livestock (Mardani and Jahromi, 2007).

\section{Clinical features and pathogenesis}

CCHFV infections are asymptomatic in animals and birds are thought to be resistant. Humans are the main victims to this disease. The course of the disease can be divided into four phases- incubation, pre-hemorrhagic, hemorrhagic and convalescence. The incubation period depends on the mode of infection. Infections acquired via tick bites usually become apparent after 1-3 days. Exposure to blood ortissues results in longer incubation period. In Indian cases, the incubation period ranged from 7-12 days through the later mode (Patel, et al., 2011).
Pre-hemorrhagic symptoms are non-specific and include fever, chills, severe headache, dizziness, photophobia, myalgia and arthralagia. This phase may last for 1-7 days. The hemorrhagic phase develops suddenly lasting for 2-3 days (Saijo and Morikawa, 2010). A petechial rash may be the first symptom both on the internal mucosal surfaces such as mouth and throat and on the skin. They are followed by ecchymoses and other hemorrhagic phenomenon such as hematemesis, melena, epistaxis, hematuria, and hemoptysis. Hepatomegaly and spleenomegaly can be seen in some patients (Appannanavar and Mishra, 2011). There may be rapid kidney deterioration. Death may occur in many cases. The mortality rate is $30 \%$ and the case fatality rate is up to $40 \%$. In Indian cases death occurred due to cardio respiratory arrest, multiorgan failure and disseminated intravascular coagulation (DIC) and gastrointestinal bleeding in one case (Mourya, et al., 2012). Thrombocytopenia occurs and dysregulation of the coagulation cascade leads to DIC. Proinflammatory cytokines are important in pathogenesis and the IL-6and TNF- $\alpha$ level are significantly higher in fatal CCHF.A study shows that viral genome can be detected from saliva and urine of infected patient. In CCHF there is increased serum ferritin level which can be used as a marker for disease activity and prognosis.

\section{Public health importance}

Humans readily succumb to $\mathrm{CCHFV}$ infection. However domestic animals are either refractory or undergo mild infection with transient viremia sometimes, but they act as a main source of infection for humans (Prajapati, et al., 2011). Persons living in close contact with animals are at the high risk of getting $\mathrm{CCHF}$. Veterinarians and farmers may castrate, dehorn, attach ear tags and immunize young animals and thus expose 
themselves to the virus infected blood. They may have broken skin or scratch on the skin through which they may get infected. Consumption of unboiled or uncooked meat and milk of infected animal may be a potential source of infection (Ergonul, 2006). There is lack of evidence of disease in urban consumers of meat but the infected animal may reach to abattoir to pose a potential threat for workers and meat consumers. Exposure to aerosols while working with infected animals and in the hospital setting are the potential hazards. The population in the infected or infection prone area should be aware of the potential routes of infection and the safety measures to be taken to avoid the infection (WHO, 2013). CCHFV may be used for bioterrorism or as a bio warfare agent (Ergonul, 2013).

\section{Diagnosis}

To save the patient and to prevent the further transmission of disease, early diagnosis is essential. The key indicators to suspect CCHF infection includes compatible clinical manifestations like fever and bleeding, history of tick bite, travel to endemic area and contact with infected cases and tick infested animals. The disease should be differentiated from the other VHFs, malaria, dengue, yellow fever, Kyasanur forest disease, rickettsiosis and leptospirosis (Mishra, et al., 2011). The knowledge of ecology and endemicity of CCHFV should be kept in mind to proceed with further diagnosis. The methods of diagnosis include virus isolation, immunological assays like ELISA and molecular diagnostic methods like reverse transcription- polymerase chain reaction (RTPCR) (Ergonul, 2013). CCHFV can be isolated from the blood, plasma and tissue of infected patient for the diagnosis. Virus isolation should be performed in a high biocontainment laboratory. A variety of cell lines including vero, BHK-21, LLC-MK2 and SW-
13 can be used for virus culture. Cell culture can detect only high virus concentration and only useful during first five days of disease. Generally, the virus produces no or little cytopathic effects so it can be identified by immunofluorescence assay using specific monoclonal antibodies (Whitehouse, 2004). The traditional method of animal inoculation of newborn mice is more sensitive than cell culture and also detects the virus for longer period. The virus isolation by cell culture is of limited value because it needs a biosafety level-4 laboratory (BSL-4) which is unavailable in most of the endemic areas (Ergonul, 2013). In the first few days of illness usually the patients do not develop a measurable antibody response so the serological tests are useful in the second week of illness. There are various serological tests available for detection of CCHFV but these tests are of limited use in fatal cases as patients generally die without developing antibodies. The conventional serological test for CCHFV like Complement fixation, heamagglutination inhibition and immuno diffusion suffered lack of sensitivity and reproducibility. This problem was solved by Indirect Immuno fluorescence assay (IFA) and Enzyme-linked immunosorbent assay (ELISA) for the detection of IgM and IgG antibodies. Both IgM and IgG can be detected up to 7-9 days of illness by indirect FIA. ELISA has replaced the conventional methods for antibody detection. IgM can be detected up to 4 months and $\operatorname{IgG}$ persist for 5 years post - infection but its level decrease.

Molecular diagnostic assays such as reverse transcriptase polymerase chain reaction now serve as the front-line tool in the diagnosis of CCHF. PCR based methods are sensitive, specific, rapid and can be done without the need to culture the virus which requires BSL4 facility. Molecular epidemiology can also be performed by this technique. A further improvement on the conventional RT-PCR 
assay has been the advent of automated realtime PCR based assays. The real-time PCR is more advantageous over conventional RTPCR methods with respect to sensitivity, specificity and time taken for detection. Realtime PCR also offers less contamination rate. There are various detection chemistries available for the real time PCR like SYBR green, TaqMan and molecular beacon etc. There are several real-time RT-PCR assays reported till now for CCHFV detection. Some important assays developed for CCHFV detection are SYBR green, TaqMan and TaqMan-Minor Groove Binding (MGB) probe based assays(Garrison, et al., 2007).

\section{Treatment}

In case of CCHF, treatment is mainly supportive. It includes careful management of fluid and electrolyte balance depending upon the severity of illness. Currently there is no specific antiviral therapy for CCHF approved by United States Food and Drug Administration (FDA) for human use (Khan, et al., 2011). Ribavirin, a guanosine analogue is found effective against CCHFV(Izadi and Salehi, 2009). In India one case recovered by the oral administration of ribavirin and discharged after ten days(Mishra, et al., 2011). Passive immunotherapy using specific immunoglobulin CCHF-Venin is also found beneficial in CCHFV treatment (Khan, et al., 2011).

\section{Prevention and control}

The prevention and control should be both at community level as well as in nosocomial set up. Minimizing human contact with suspected livestock and reducing the tick burden in the animals are the primary and most important preventive measures (WHO, 2013). Animals should be carefully monitored for tick infestation and treated by appropriate acaricidal agents particularly before slaughter or export. Wearing fully covered clothes and use of tick repellent is recommended to prevent tick attachment on the body surface. The unpasteurized milk and uncooked meat should not be taken. Human- to- human infection mainly occurs in the nosocomial setup by the contact of infected blood or tissue. So use of protective clothing, gloves, goggles and face-masks reduces the chances of exposure (Bajpai and Nadkar, 2011). Safe burial practices with proper use of disinfectants should be followed. Veterinarians, research workers, slaughter house workers and medical professionals should take utmost care to reduce the contact with suspected material. They should take the prophylactic treatment after high risk exposure. Laboratory and research workers are advised to follow stringent biosafety precautions during handling the pathogen and the work should be carried out underBSL-4 facilities. Virus can be inactivated by using $1 \%$ hypochlorite and 2\% glutaraldehyde. Heating at $56^{\circ} \mathrm{C}$ for 30 minutes also destroy the virus (Saijo and Morikawa, 2010).

\section{Vaccination}

Vaccine against $\mathrm{CCHF}$ is not available inmost of the countries. However, a formalin inactivated vaccine derived from suckling mouse brain has been used in Bulgaria and former Soviet Union (Papa, et al., 2011). There is no vaccine available for animal use(WHO, 2013).

CCHF is an important tick borne multi systemic zoonotic disease the ability to cause death in human beings

Now CCHF is worldwide in distribution and has been reported from most of the countries including India

Tick bite, contact with infected material and nosocomial routes are the main routes of infection 
Hyalomma tick is the main vector

This disease is not much important in animals as animals are asymptomatic but domestic livestock play a vital role in the transmission of disease to humans

Climatic change is always a contributing factor for the occurrence of disease that affects the reproduction of tick population resulting in increased incidence of tick born infections

Persons associated with animals like veterinarians, farmers and slaughter house workers are also at the high risk of getting the infection

Disease can be controlled and prevented by personal protection, tick control and early stage treatment

Ribavirin antiviral drug is the choice of treatment applicable only in early stage of disease

\section{References}

Appannanavar, S.B. and Mishra, B. (2011)An Update on Crimean-Congo Haemorrhagic Fever. J. Glob. Infect. Dis., 3(3): 285-292.

Bajpai, S. and Nadkar, M.Y. (2011) Crimean Congo Haemorrhagic Fever: Requires Vigilance and Not Panic J.A.P.I., 59:164-167.

Casals, J. (1969) Antigenic similarity between the virus causing Crimean hemorrhagic fever and Congo virus. Proc.Soc. Exp. Biol. Med., 131: 233-236.

Ergonul, O. (2006) Crimean-Congo haemorrhagic fever. Lancet Infect. Dis., 6: 203-14.

Ergonul, O.

(2013)Crimean-Congo haemorrhagic fever virus: new outbreaks, new discoveries. Current Opinion inVirology, 2:215-220.

Estrada-Pena, A. (2001) Forecasting habitat suitability for ticks and prevention of tick-borne diseases. Vet. Parasitol., 98:111-132.
Garrison, A.R., Alakbarova, S., Kulesh, D.A., Shezmukhamedova, D., Khodjaev, S., Endy, T.P. and Paragas, J. (2007) Development of a TaqMan-Minor Groove Binding Protein Assay for the Detection and Quantification of Crimean-Congo Haemorrhagic Fever Virus. Am. J. Trop.Med. Hyg., 77(3): 514-520.

Izadi, S. and Salehi, M. (2009) Evaluation of the Efficacy of Ribavirin Therapy on Survival of Crimean-Congo Haemorrhagic Fever Patients. A CaseControl Study. J.Infect. Dis., 62: 11-15.

Khan, N.A., Jaiswal, A., Choudhray, R., Abid, M. and Kishore, K. (2011) Crimean-Congo haemorrhagic fever: An article review. Int. Res. J. Pharma., 2(5): 33-40.

Maltezou, H.C. and Papa, A. (2011) CrimeanCongo hemorrhagic fever: epidemiological trends and controversies in treatment. $B M C$ Medicine, 9:131.

Mardani, M. and Jahromi, M.K. (2007) Crimean-Congo Haemorrhagic Fever.Archives of Iranian Medicine, 10(2): $204-214$.

Masayuki, S., Qing, T., Bawudong, S., Lei, H. and Yuzhen, Z. (2004) Possible horizontal transmission of CrimeanCongo haemorrhagic fever virus from a mother to her child.J.Infect. Dis., 57: 55 $-57$.

Mishra, A.C., Mehta, M., Mourya, D.T. and Gandhi, S. (2011) Crimean-Congo haemorrhagic fever in India. Lancet., 378: 372 .

Mourya, D.T., Yadav, P.D., Shete, A.M., Gurav, Y.K., Raut, C.G., Jadi, R.S., Pawar, S.D., Nichol, S.T. and Mishra, A.C. (2012) Detection, Isolation and Confirmation of Crimean-Congo Haemorrhagic Fever Virus in Human, Ticks and Animals in Ahmadabad, India, 2010-2011. PLo. SNegl. 
Trop.Dis., 6(5): 1653.

Ozdarendeli, A., Canakoglu, N., Berber, E., Aydin, K., Tonbak, S., Ertek, M., Buzgan, T., Bolat, Y., Aktas, M. and Kalkan, A. (2010)The complete genome analysis of Crimean-Congo hemorrhagic fever virus isolated in Turkey. Virus Research, 147: 288-293.

Palomar, A.M., Portillo, A., Santibáñez, P., Mazuelas, D., Arizaga, J., Crespo, A., Gutierrez, O., Cuadrado, J.F. and Oteo, J.A. (2013)Crimean-Congo Haemorrhagic Fever Virus in Ticks from Migratory Birds, Morocco. Emerg. Infect.Dis., 19 (2):260-263.

Papa, A., Papadimitriou, E. and Christova, I. (2011) The Bulgarian vaccine CrimeanCongo haemorrhagic fever virus strain. Scand J. Infect. Dis., 43:225-9.

Patel, A.K., Patel, K.K., Mehta, M., Parikh, T.M., Toshniwal, H. and Patel, K. (2011) First Crimean-Congo Haemorrhagic Fever Outbreak in India. J.A.P.I., 59: 585-88.

Prajapati, D.S., Patel, K.M., Patel, R.K., Sen, D.J., Patel, J.S. and Garg, C.S. (2011)Crimean-congo hemorrhagic fever from tick-borne viral disease. Int. J. Compreh. Pharm., 3(2). 1-6.
Saijo, M. and Morikawa, S. (2010) Recent progress in the treatment of CrimeanCongo haemorrhagic fever and future perspectives. Future virology, 5(6): 801-9.

Sheikh, A.S., Sheikh, A.A., Sheikh, N.S., Rafi, U.S., Asif, M. and Afridi, F. (2005) Bi-annual surge of CrimeanCongo hemorrhagic fever (CCHF): a five-year experience. Int. J.Infect. Dis., 9: 37-42.

Whitehouse, C. A. (2004) Crimean-Congo haemorrhagic fever. Antiviral Res., 64: 145-160.

World Health Organization (2013) WHO Fact Sheet No. 208. WHO, Geneva, Switzerland.

Yadav, P.D., Cherian, S.S., Zawar, D., Kokate, P., Gunjikar, R., Jadhav, S., Mishra, A.C. and Mourya, D.T. (2013) Genetic characterization and molecular clock analyses of the Crimean-Congo haemorrhagic fever virus from human and ticks in India, 2010-2011. Infection, Genetics and Evolution, 14: 223-231.

Zavitsanou, A., Babatsikou, F. and Koutis, C. (2009) Crimean Congo Haemorrhagic fever: an emerging tick-borne disease. Health Science Journal, 3(1):10-18.

\section{How to cite this article:}

Sindhi. S. H., K. R. Bhedi, J. B. Kathiriya and Ghodasara. S. N. 2020. Crimean Congo Haemorrhagic Fever: An Emerging Tick-borne Metazoonosis. Int.J.Curr.Microbiol.App.Sci. 9(06): 2368-2375. doi: https://doi.org/10.20546/ijcmas.2020.906.290 